\title{
Changes in the expressions of E-selectin, adiponectin and serum ferritin in patients with diabetic retinopathy, and their correlations
}

\author{
Zhou Li $^{1 \star}$, Zhou Zheng ${ }^{2}$, Wei Xiaodan ${ }^{2}$, Tian Bin ${ }^{3}$, Ji Yuanhong ${ }^{3}$ \\ ${ }^{1}$ Ophthalmology Department, Tangshan City Workers Hospital Group Rehabilitation Hospital, ${ }^{2}$ Ophthalmology Department, \\ Tangshan City Workers Hospital, ${ }^{3}$ The Department of Rehabilitation, Tangshan City Workers Hospital Group Rehabilitation \\ Hospital, Tangshan, Hebei 063000, China
}

*For correspondence: Email: vb1336@163.com

Sent for review: 9 April 2018

Revised accepted: 28 June 2018

\begin{abstract}
Purpose: To study changes in the expressions of E-selectin, adiponectin (APN) and serum ferritin in patients with diabetes retinopathy $(D N)$ and their correlations with $D N$.

Methods: Diabetes patients (180) in Tangshan City Workers Hospital Group Rehabilitation Hospital from February 2014 to February 2015 were recruited and divided into three groups: 56 non-diabetic retinopathy (NDR) cases, 60 non-proliferative diabetic retinopathy (NPDR) cases and 64 proliferative diabetic retinopathy (PDR) cases. Serum levels of E-selectin, adiponectin (APN), ferritin (SF), fasting plasma glucose (FPG) and fasting insulin (FINS) were separately assayed, and their correlations analyzed.

Results: There were no significant differences between patients in the three groups with respect to sex, age, blood pressure and blood lipids ( $p>0.05$ ). Serum E-selectin, APN and SF levels gradually and significantly increased in the order: NDR group $<$ NPDR group $<$ PDR group $(p<0.05)$.

Conclusion: E-selectin, $A P N$ and $S F$ levels of patients with $D N$ increase with aggravation of the disease. The decrease in E-selectin, APN and SF levels may have a positive effect on the improvement of the status of DN patients.
\end{abstract}

Keywords: Diabetic retinopathy, E-selectin, Adiponectin, Serum ferritin

\begin{abstract}
This is an Open Access article that uses a funding model which does not charge readers or their institutions for access and distributed under the terms of the Creative Commons Attribution License (http://creativecommons.org/licenses/by/4.0) and the Budapest Open Access Initiative (http://www.budapestopenaccessinitiative.org/read), which permit unrestricted use, distribution, and reproduction in any medium, provided the original work is properly credited.

Tropical Journal of Pharmaceutical Research is indexed by Science Citation Index (SciSearch), Scopus, International Pharmaceutical Abstract, Chemical Abstracts, Embase, Index Copernicus, EBSCO, African Index Medicus, JournalSeek, Journal Citation Reports/Science Edition, Directory of Open Access Journals (DOAJ), African Journal Online, Bioline International, Open-J-Gate and Pharmacy Abstracts
\end{abstract}

\section{INTRODUCTION}

Diabetic retinopathy (DR) is a common microvascular complication of type 2 diabetes mellitus (T2DM), and a major cause of blindness in diabetic patients [1]. It imposes severe threat to the health and safety of life of patients. Retinopathy in diabetes is caused by microvascular changes in the retina, which affect retinal function. The mechanism of DR onset is still unclear. However, it is generally believed that it is related to the microvascular system injury of retina, generation of extracellular matrix vessels, proliferation of vascular cells, changes in the coagulation fiber system, and inflammatory reactions. 
Serum ferritin (SF) plays an important role in activating stress reactions and inflammatory reactions. It is the most abundant protein in the body, the main storage form of iron, and a marker of iron storage, which participates in multiple physiological and pathological processes. It is a sensitive marker of iron metabolism in clinics. In recent years, studies have shown that iron metabolism in vivo (iron overload caused by excessive iron) is closely linked to abnormal lipid metabolism and atherosclerosis [2]. Abnormal SF metabolism may be implicated in the etiology of type 2 diabetes.

A fat factor secreted by adipose tissue, APN improves insulin resistance, resists atherosclerosis, and negatively regulates immune reactions. It may block development of microvascular lesions in diabetes, especially DR.

Adhesion molecule, a glycoprotein which participates in regulating interaction between cells, and between cell and ECM, is expressed in cell surface in connection with a specific receptor. E-selectin, also called CD62 E, is a member of adhesion molecular selectin family. It is expressed in activated vascular endothelial cell surface and mediates interaction between leukocyte only in vascular endothelial cells, thus playing an important role in the process of cell injury, vascular occlusion and new vessel generation. It is highly expressed after stimulation of vascular endothelial cells, and it enters the blood, forming E-selectin. It can be a specific marker of endothelial injury in clinics [3].

Adiponectin, E-selectin, and serum ferritin of patients with $\mathrm{DR}$, and their correlations were investigated in this study.

\section{METHODS}

\section{General data}

Diabetic patients (180) in $X X$ hospital from February, 2014 to February m 2015 were recruited as study subjects. According to results of funduscopy and fundus fluorescein angiographs, T2DM patients with accurate diagnosis were divided into three groups: 56 NDR cases, 60 NPDR cases and 64 PDR cases. This research was approved by the Ethical Committee of Tangshan City Workers Hospital Group Rehabilitation Hospital (approval no. 201703214) was in accordance with the guidelines of the Declaration of Helsinki promulgated in 1964 as amended in 1996 [4], the.

\section{Diagnostic criteria}

Diagnostic criteria were in accordance with relevant criteria of type 2 diabetes in Internal Medicine. Patients with fasting blood sugar (FBS) $\geq 7.0 \mathrm{mmol} / \mathrm{L}$, or $\mathrm{PBG} \geq 11.1 \mathrm{mmol} / \mathrm{L}$ were deemed diabetic. The diagnostic criteria for DR were consistent with the standards set by the Fundus Diseases Cooperative Group in 1984.

\section{Methods}

The sex, age and disease history of the patients were recorded. Venous blood $(6 \mathrm{ml})$ samples were taken in plain bottles after $8 \mathrm{~h}$ fast, and centrifuged at $3000 \mathrm{rpm}$ for $10 \mathrm{~min}$. The serum samples obtained were kept refrigerated at $4{ }^{\circ} \mathrm{C}$ prior to use. Blood pressure, TC, TG, HbA1C, HDL-C, LDL-C, FINS, FPG, Scr and Ccr were determined through Automatic biochemical analyzer. ELISA kits were used to measure levels of E-selectin, APN and SF.

\section{Statistical analysis}

SPSS 19.0 was used to analyze all data. Measurement data are presented as mean $\pm S D$, and analyzed with Student's $t$-test. Significance level was set at $p<0.05$.

\section{RESULTS}

\section{General clinical data}

Table 1 shows that there were no significant differences between patients in the three groups with respect to sex and age $(p>0.05)$. However, there were significant differences in NDR, NPDR and PDR in disease history $(p<0.05)$. Disease history in NDR group, NPDR group and PDR group increased gradually.

Table 1: General clinical data for the patients

\begin{tabular}{lccc}
\hline Group & NDR & NPDR & PDR \\
\hline Male/female & $27 / 29$ & $28 / 32$ & $33 / 31$ \\
Age & $57.45 \pm 9.41$ & $57.17 \pm 8.96$ & $59.12 \pm 6.01$ \\
Disease & $4.23 \pm 3.26$ & $7.64 \pm 5.68^{*}$ & $10 \pm 5.49^{\#}$ \\
duration (years) & & & \\
$\begin{array}{l}\text { Systolic BP } \\
\text { (mmHg) }\end{array}$ & $127.05 \pm 18.41$ & $126.51 \pm 23.58$ & $132.16 \pm 16.39$ \\
$\begin{array}{l}\text { Diastolic BP } \\
\text { (mmH) }\end{array}$ & $79.30 \pm 9.83$ & $82.05 \pm 12.17$ & $83.68 \pm 12.34$ \\
\hline $\begin{array}{l}\text { BP, Blood pressure; Values are mean } \pm \text { SD. }{ }^{*} p<0.05, \\
\text { compared with }\end{array}$ & NDR group ; \# $p<0.05$, compared with \\
NPDR group & &
\end{tabular}

\section{Biochemical indices}

Patients in NDR, NPDR and PDR groups had no significant differences amongst them with respect to TC, TG, HbA1C, HDL-C, LDL-C, FINS and 
FPG $(p>0.05)$. However, there were significant differences amongst patients in the three groups with respect to Scr, Ccr, E-selectin, APN and SF $p<0.05)$. There were gradual increases in the levels of E-selectin, APN and SF in the order NDR group < NPDR group < PDR group, i.e. PDR group was significantly higher than NPDR group, which was significantly higher than NDR group $(p<0.05)$ (Table 2$)$.

Table 2: Biochemical data for the patients

\begin{tabular}{lccc}
\hline Group & NDR & NPDR & PDR \\
\hline TC (mmol/L) & $5.08 \pm 1.12$ & $5.44 \pm 1.33$ & $6.23 \pm 1.07$ \\
TG (mmol/L) & $1.36 \pm 1.01$ & $1.45 \pm 0.42$ & $1.77 \pm 1.25$ \\
HbA1C (\%) & $8.36 \pm 4.20$ & $8.55 \pm 1.57$ & $8.77 \pm 1.16$ \\
HDL-C & $1.38 \pm 0.26$ & $1.41 \pm 0.27$ & $1.43 \pm 0.35$ \\
(mmol/L) & & & \\
LDL-C & $2.81 \pm 1.20$ & $2.72 \pm 0.88$ & $2.78 \pm 1.07$ \\
(mmol/L) & & & \\
FINS (mU/L) & $8.89 \pm 7.16$ & $8.72 \pm 5.91$ & $8.66 \pm 7.02$ \\
FPG & $11.41 \pm 5.15$ & $11.54 \pm 4.07$ & $11.88 \pm 4.17$ \\
(mmol/L) & & & \\
Scr (mol/L) & $65.54 \pm 31.61$ & $81.90 \pm 51.88^{*}$ & $101.39 \pm 62.17^{\#}$ \\
Ccr (ml/min) & $99.64 \pm 27.86$ & $91.39 \pm 29.51$ & $76.40 \pm 26.45^{\#}$ \\
E-selectin & $25.11 \pm 7.85$ & $32.72 \pm 5.35^{*}$ & $44.11 \pm 9.92^{\#}$ \\
(pg/mL) & & & \\
APN (mg/L) & $5.12 \pm 2.77$ & $6.84 \pm 3.49^{*}$ & $8.97 \pm 4.83^{\#}$ \\
SF (ug/L) & $188.62 \pm 65.61$ & $247.08 \pm 70.92^{*}$ & $283.59 \pm 49.73^{\#}$ \\
\hline Values are mean \pm SD. ${ }^{*} p<0.05$, compared with NDR \\
group, ${ }^{\#} p<0.05$, compared with NPDR group
\end{tabular}

\section{Single factor correlation of E-selectin, APN} and SF with other indices

There was a positive correlation between SF and levels of TC, while LDL-C was negatively correlated with HDL-C; APN had positive correlation with Scr, but was negatively correlated with TC, LDL-C, FINS and Ccr. Eselectin was positively correlated with $\mathrm{HbA} 1 \mathrm{C}$. These results are shown in Table 3.

\section{DISCUSSION}

Iron is an essential microelement for humans. It is needed for maintaining normal physiological functions, and it also influences normal circulation of endocrine system [6]. Serum ferritin
(SF) is the major storage form of iron in the human body. Studies have shown that abnormal iron metabolism is closely linked to increased blood glucose, and that iron over-load influences insulin function [7]. Indeed, abnormal iron metabolism may be deleterious to endocrine function of insulin cells, thus causing T2DM [8]. Diabetic retinopathy (DR) is one of the chronic complications of diabetes. It is caused by microvascular lesions, and results in irreversible visual impairment. Effective control of FBS does not retard the progression of DR.

Increased SF level can influence glucose metabolism, blood viscosity, and oxidative stress. Therefore, it may be closely related to the incidence of DR. Studies have reported higher SF levels in DR patients than in NDR patients [9]. In the course of the disease, serum protein concentration increases, which indicates that serum SF is correlated with DR.

When blood glucose is elevated, it can activate oxidative stress reactions and stimulate retinal chromocytes to secrete activation oxidants. Excessive oxidants injure microvessels in retina and accelerate apoptosis, leading to retinal lesions [10-12]. The levels of inflammatory factors increase with progression of the disease, and cause further retinal lesions. Therefore, the longer the course of diabetes, the more severe the retinal lesion becomes $[13,14]$. This is in accordance with results of obtained in the present study. Previous studies have shown an association between DR and APN $[15,16]$.

In this study, serum APN was highest in the PDR group. This trend is consistent with existing literature. Several derangements due to macrovascular complications of diabetes, such as disorders of glucose metabolism and insulin resistance are correlated with APN. It has been reported that APN can stimulate vascular hyperplasia, thereby accelerating development of retinal lesions [17]. The mechanism underlying

Table 3: Analysis of correlation between E-selectin, APN and SF, and other indices

\begin{tabular}{lcccccc}
\hline \multirow{2}{*}{ Parameter } & \multicolumn{2}{c}{ SF } & \multicolumn{2}{c}{ ADP } & \multicolumn{2}{c}{ E-selectin } \\
\cline { 2 - 7 } & $\boldsymbol{R}$ & $\boldsymbol{p}$ & $\boldsymbol{r}$ & $\boldsymbol{p}$ & $\boldsymbol{R}$ & $\boldsymbol{p}$ \\
\hline TC $(\mathrm{mmol} / \mathrm{L})$ & 0.361 & $0.049^{*}$ & -0.252 & $0.022^{*}$ & 0.479 & 0.342 \\
TG (mmol/L) & 0.135 & 0.477 & -0.154 & 0.157 & 0.274 & 0.489 \\
HbA1C (\%) & 0.253 & 0.766 & 0.219 & 0.287 & 0.284 & $0.046^{*}$ \\
HDL-C (mmol/L) & -0.454 & $0.021^{*}$ & 0.028 & 0.856 & 0.043 & 0.784 \\
LDL-C (mmol/L) & 0.679 & $0.013^{*}$ & -0.235 & $0.034^{*}$ & 0.583 & 0.548 \\
FINS (mU/L) & -0.007 & 0.882 & -0.367 & $0.011^{*}$ & -0.281 & 0.793 \\
FPG (mmol/L) & 0.045 & 0.820 & 0.021 & 0.853 & 0.043 & 0.742 \\
Scr (mol/L) & 0.534 & 0.167 & 0.442 & $0.039^{*}$ & 0.492 & 0.266 \\
Ccr (ml/min) & 0.481 & 0.734 & -0.267 & $0.038^{*}$ & 0.398 & 0.833 \\
\hline${ }^{*} P<0.05$ & & & & & &
\end{tabular}


the observed increase in APN in DR patients is not very clear. However, it might be due to either an increase in the synthesis of APN, or decrease in its degradation. The protein APN is closely linked with diabetic atherosclerosis, which it inhibits by inhibiting production of atherosclerotic factors. A study of diabetic patients high APN levels in the high-SCr group [18]. Serum APN level has positive correlations with SCr. In this study, with disease progression, there were gradual decreases in degradation of $\mathrm{Ccr}$ in the order NDR group > NPDR group > PDR. This trend shows that the increased APN level may be caused by decreased rate of its degradation.

Adhesion molecule, which participates in regulating interactions between cells, and between cells and ECM, is expressed on the cell surface and is linked with a specific receptor, which implies that it plays a biological role. The occurrence of adhesion in DR has increasingly attracted research attention. High blood glucose causes disordered intracellular metabolism and changes in hemodynamics. In addition, it injures endothelial cells, increases E-selectin expression, and induces adhesion of leucocyte, thus producing inflammatory reactions.

Studies have demonstrated that high blood glucose increases the expression of E-selectin, and that $\mathrm{sE}$-selectin has significant correlation with blood glucose $[19,20]$. Leucocytes induced by E-selectin and adhesion processes in vascular endothelial cells play an important role in three stages i.e. capillary endothelial injury, capillary occlusion and new vessel generation. High blood glucose and glycosylated hemoglobin in blood can directly act on vascular endothelial cells, and activate the expression of E-selectin, which then adheres to vascular endothelial cells. At the same time, endothelial tissue injury also promotes the expression of E-selectin. Endothelial cell injury causes leucocyte infiltration into retinal tissue, thus leading to disorder in microvascular circulation and injury of retinal surrounding tissue, which ultimately causes irreversible lesions on retinal surrounding microvessels. Diabetic retinopathy is induced by an interplay of several factors, but the exact mechanisms responsible for its incidence requires further studies.

\section{Limitations of the study}

Few participants were included in this study and all of them are from one center. Whether the conclusion in this research can be generalized to other places is still uncertain.

\section{CONCLUSION}

E-selectin, APN and SF levels of patients with DN increase with aggravation of the disease. Reduction in the levels of these parameters may have a positive effect on the improvement in the health status of DN patients.

\section{DECLARATIONS}

\section{Conflict of Interest}

No conflict of interest associated with this work.

\section{Contribution of Authors}

We declare that this work was done by the author(s) named in this article and all liabilities pertaining to claims relating to the content of this article will be borne by the authors, all authors read and approved the manuscript for publication. $\mathrm{Ji}$ Yuanhong conceived and designed the study, Zhou Zheng, Wei Xiaodan, Tian Bin collected and analyzed the data, Zhou Li wrote the manuscript.

\section{REFERENCES}

1. Geng $P L$, Ding $Y Y$, Qiu L, Lu YY. Serum mannosebinding lectin is a strong biomarker of diabetic retinopathy in Chinese patients with diabetes. Diabetes Care 2015; 38: 868-875.

2. Maher V, Odown M, Carey M, Markham C, Byrne A, Hand E, Mc Inerney D. Association of central obesity with early carotid intima-media thickness is independent of that from other risk factors. In J Obes (Lond) 2009; 33 (1): 136-143.

3. Bluher $M$, Unger $R$, Rassoul $F$, Richter $V$, Paschke $R$. Relation between glycaemic control, hyperinsulinaemia and plasma concentrations of soluble adhesion molecules in patients with impaired glucose tolerance or Type II diabetes. Diabetologia 2002; 45 (2): 210-216.

4. World Health Organization. Declaration of Helsinki. Br Med J 1996; 313 (7070): 1448-1449.

5. Cheung N, Mitchellp, Wong TY. Diabetic retinopathy. Lancet 2010; 376 (9735): 124-136.

6. Gorokhova SG, Atamanova MA, Muraseeva EV. The evaluation of iron exchange parameters in patients with coronary atherosclerosis and type 2 diabetes mellitus. Klin Med (Mosk) 2007; 85 (11): 50-54.

7. Li M, Fang F. Related analysis on type 2 diabetes and trace elements. Guangdong Trace Elem Sci 2012; 19 (3): $1-4$.

8. Lan LZ, Wang MY, Yang J. Analysis on the relationship between insulin resistance and the concentration of serum ferritin, transferrin in type 2 diabetes mellitus. Chin Med Herald 2013; 10 (18): 52-54.

9. Zong CX, Peng YY, Zhang GS. Relationship among SF and type 2 diabetes and diabetic retinopathy. J Hebei Med Univ 2013; 34(7): 764-766.

Trop J Pharm Res, July 2018; 17(7): 1436 
10. Jiang $Y$, Miu $H$. Serum $C$-reactive protein, serum ferritin and its relationship with the severity of diabetic retinopathy. J Clin Med Prac 2012; 16 (17): 150-152.

11. Duh EJ, Sun JK, Stitt AW. Diabetic retinopathy: current understanding, mechanisms, and treatment strategies. JCl Insight 2017; 2 (14): e93751.

12. Kowluru RA, Chan PS. Oxidative stress in diabetic retinopathy. Exp Diabetes Res 2007; 2007: 43603.

13. $X u X H$, Chen XL, Liu HN. Relationship between diabetic retinopathy and inflammatory reaction and cytokine. Int J Ophthalmol 2009; 9 (11):2136-2138.

14. Momeni A, Behradmanesh MS, Kheiri S, Abasi F. Serum ferritin has correlation with HbA1c in type 2 diabetic patients. Adv Biomed Res 2015; 4: 74-76.

15. Zietz B, Buechler C, Kobuch $K$, Neumeier $M$, Scholmerich J, Schaffler A. Serum levels of adiponectiin are associated with diabetic retinopathy and with adiponectin gene mutations in Caucasian patients with diabetes mellitus type 2. Exp Clin Endocr Diab 2008; 116 (9): 532-536.

16. Kato K, Osawa H, Ochi $M$, Kusunoki $Y$, Ebisui O, Ohno $K$, Ohashi J, Shimizu I, Fujii $Y$, Tanimoto $M$ et al. Serum total and high molecular weight adiponectin levels are correlated with the severity of diabetic retinopathy and nephropathy. Clin Endocrinol (Oxf) 2008; 68 (3): 442449.

17. Shibata R, Ouchi N, Kihara S, Sato K, Funahashi $T$, Walsh $K$. Adiponectin stimulates angiogenesis in response to tissue ischemia through stimulation of ampactivated protein kinase signaling. J Biol Chem 2004; 279 (27): 28670-28674.

18. Looker HC, Krakoff J, Funahashi T, Matsuzawa $Y$, Tanaka S, Nelson RG, Knowler WC, Lindsay RS, Hanson RL. Adiponectin concentrations are influenced by renal function and diabetes duration in Pima Indians with type 2diabetes. J Clin Endocrinol Metab, 2004; 89: 4010-4017.

19. Olson JA, Whitelaw CM, McHardy KC, Pearson DW, Forrester JV. Soluable leucocyte adhesion molecules in diabetic retinopathy stimulate retinal capillary endothelial cell migration. Diabetologia, 1997; 40 (2): 1166-1171.

20. Blann AD, Lip GY. Cell adhesion molecules in cardiovascular disease and its risk fact or what can soluble levels tell us. J Clin Endocrinol Metab, 2000; 85 (1): 1745-1747. 